Corrigendum

\title{
Corrigendum to "Solution of Radiative Transfer Equation with a Continuous and Stochastic Varying Refractive Index by Legendre Transform Method"
}

\author{
R. Baazaoui ${ }^{1}$ and M. Gantri ${ }^{2}$ \\ ${ }^{1}$ Department of Mathematics, Faculty of Sciences of Tunis, Tunis El-Manar University, 1060 Tunis, Tunisia \\ ${ }^{2}$ Unit of Thermal Radiation, Department of Physics, Faculty of Sciences of Tunis, Tunis El-Manar University, 1060 Tunis, Tunisia \\ Correspondence should be addressed to M. Gantri; gantri.mohamed@gmail.com \\ Received 15 November 2015; Accepted 8 August 2016 \\ Copyright (c) 2016 R. Baazaoui and M. Gantri. This is an open access article distributed under the Creative Commons Attribution \\ License, which permits unrestricted use, distribution, and reproduction in any medium, provided the original work is properly \\ cited.
}

Through this corrigendum the authors declare that a version of this article entitled "Solution of Radiative Transfer Equation with a Continuous and Stochastic Varying Refractive Index by Legendre Transform Method" [1] that was published elsewhere has been retracted [2]. One of the authors of that article was missing from this article. The correct list of the authors and their affiliations are as shown above.

\section{References}

[1] M. Gantri, "Solution of radiative transfer equation with a continuous and stochastic varying refractive index by Legendre transform method," Computational and Mathematical Methods in Medicine, vol. 2014, Article ID 814929, 7 pages, 2014.

[2] "Retraction notice," Applied Mathematical Sciences, vol. 9, no. 108, p. 5399, 2015, Hikari Ltd., Ruse, Bulgaria, http://www.mhikari.com/ams/ams-2015/ams-105-108-2015/noteAMS105-1082015.pdf. 


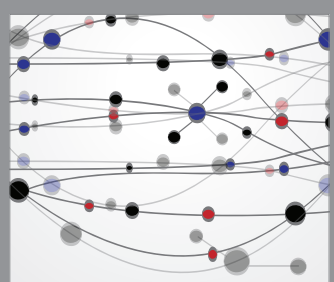

The Scientific World Journal
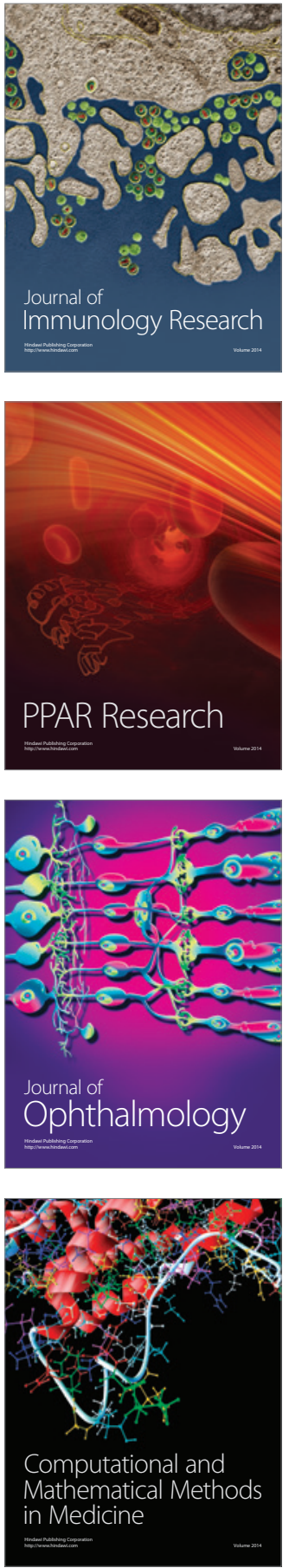

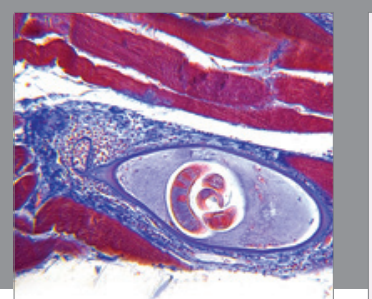

Gastroenterology Research and Practice

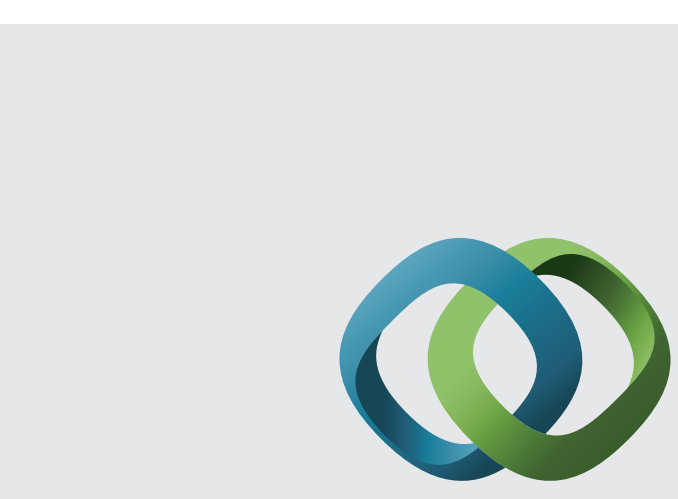

\section{Hindawi}

Submit your manuscripts at

http://www.hindawi.com
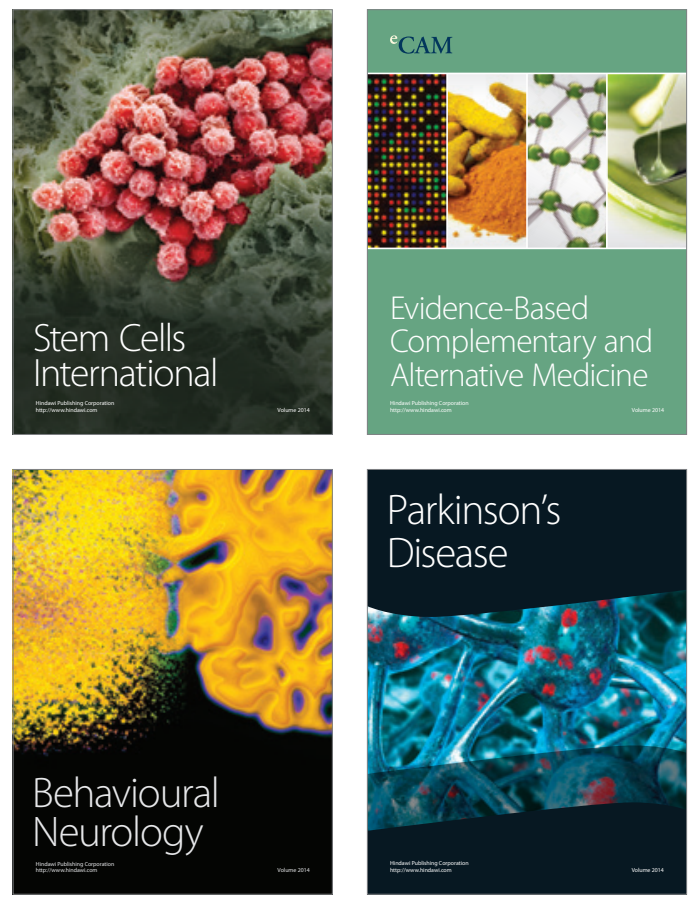
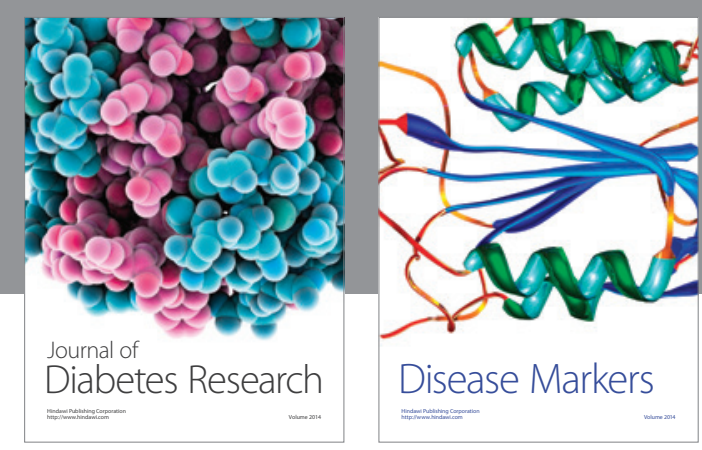

Disease Markers
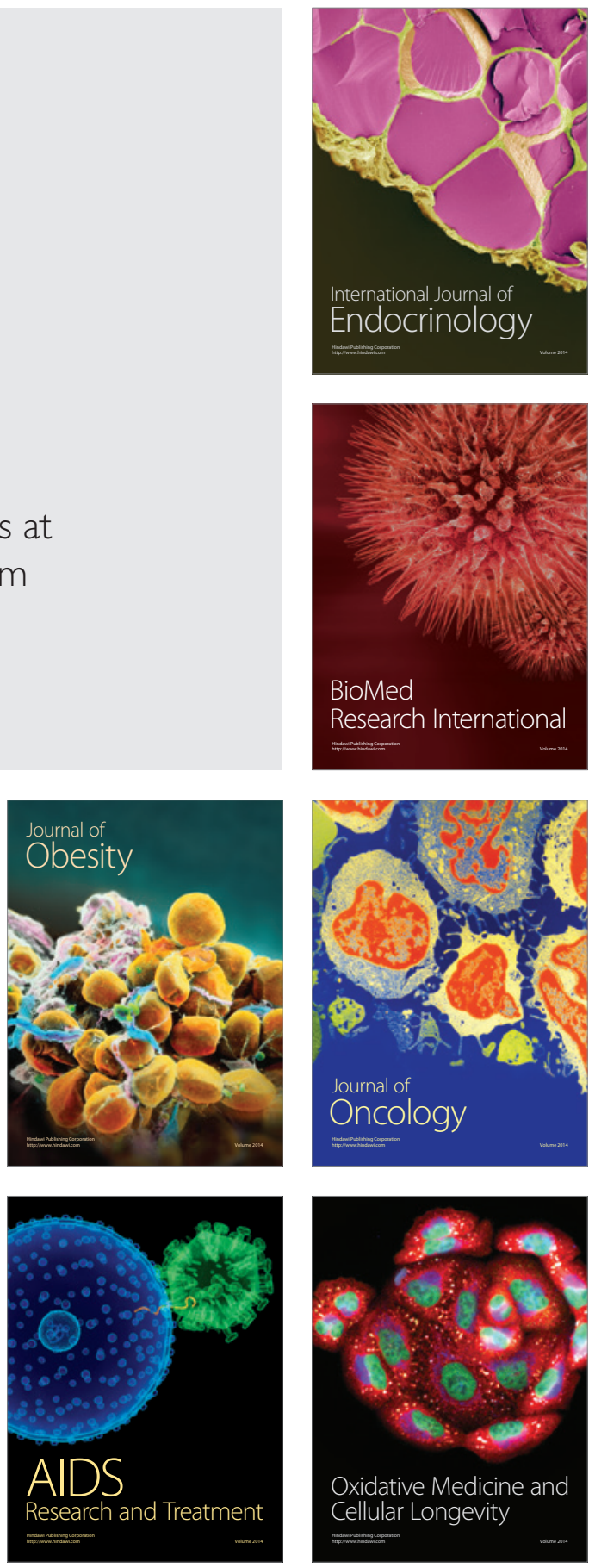